Anglada-Tort, M., Steffens, J., \& Müllensiefen, D.

\title{
Names and titles matter: The impact of linguistic fluency and the affect heuristic on aesthetic and value judgements of
} music

Journal article | Accepted manuscript (Postprint)

This version is available at https://doi.org/10.14279/depositonce-7282

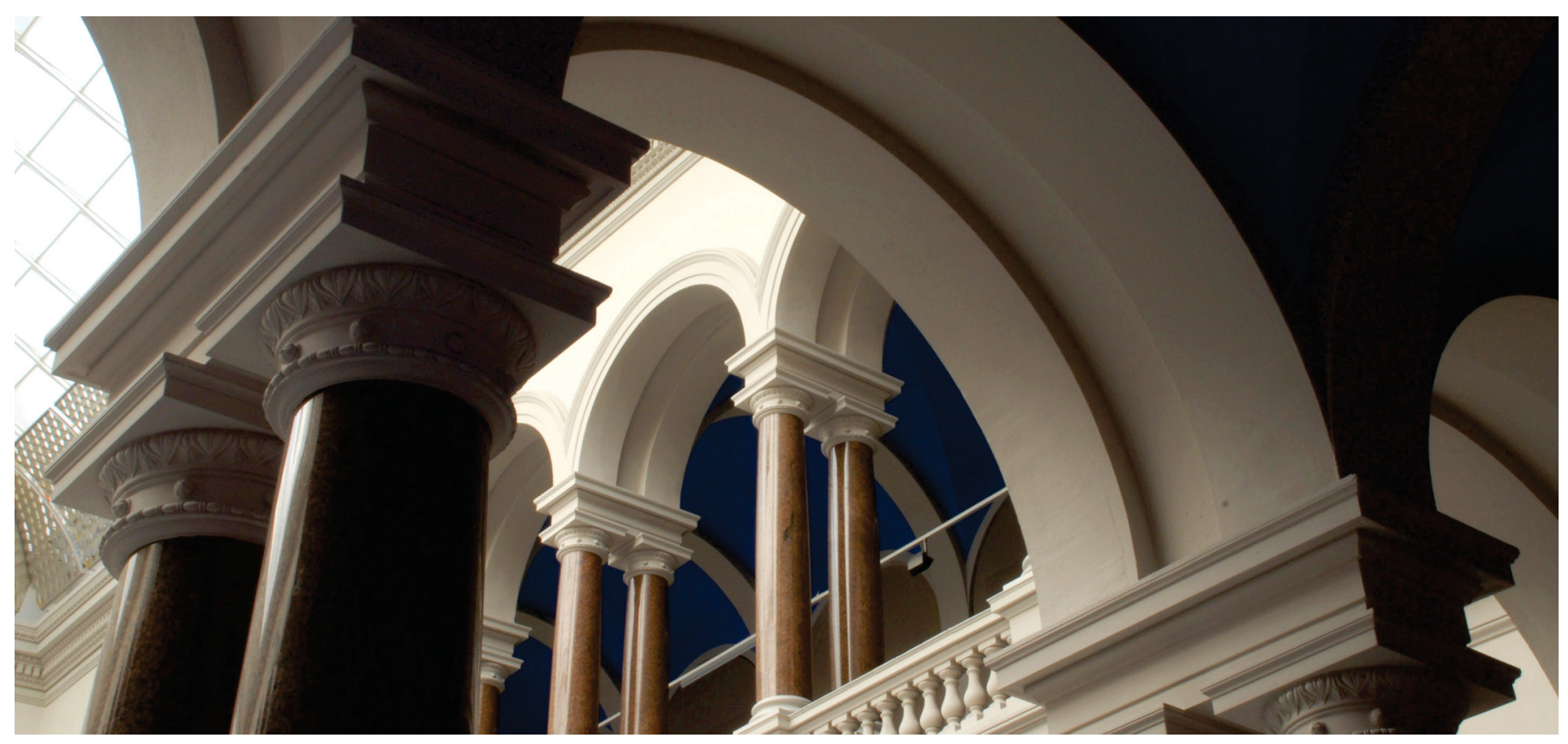

(C) American Psychological Association, 2018. This paper is not the copy of record and may not exactly replicate the authoritative document published in the APA journal. Please do not copy or cite without author's permission. The final article is available, upon publication, at: http://dx.doi.org/10.1037/aca0000172

This is an accepted manuscript (pre-print version) of an article published in Psychology of Aesthetics, Creativity, and the Arts, 05 April 2018. The "online first" version is available online at: http://psycnet.apa.org/doiLanding?doi=10.1037\%2Faca0000172

Anglada-Tort, M., Steffens, J., \& Müllensiefen, D. (2018). Names and titles matter: The impact of linguistic fluency and the affect heuristic on aesthetic and value judgements of music. Psychology of Aesthetics, Creativity, and the Arts. https://doi.org/10.1037/aca0000172

\section{Terms of Use}

Copyright applies. A non-exclusive, non-transferable and limited right to use is granted. This document is intended solely for 
Names and Titles Matter: The Impact of Linguistic Fluency and the Affect Heuristic on Aesthetic and Value Judgements of Music

Manuel Anglada-Tort and Jochen Steffens

Technische Universität Berlin

Daniel Müllensiefen

Goldsmiths, University of London

Author Note

Manuel Anglada-Tort, Department of Audio Communication, Technische Universität Berlin; Jochen Steffens, Department of Audio Communication, Technische Universität Berlin; Daniel Müllensiefen, Department of Psychology, Goldsmiths, University of London.

Correspondence concerning this paper should be addressed to Manuel Anglada-Tort, Department of Audio Communication, Technische Universität Berlin, Berlin, Germany. E-mail: m.angladatort@,campus.tu-berlin.de 


\begin{abstract}
It has been shown that titles influence peoples' evaluation of visual art. However, the question of whether titles and artist names affect listeners when evaluating music has not yet been investigated. By using two well-known cognitive heuristics, we investigated whether names presented with music pieces influenced aesthetic and value judgements of music. Experiment $1(\mathrm{~N}=48)$ focused on linguistic fluency. The same music excerpts were presented with easy-to-pronounce (fluent) and difficult-topronounce (disfluent) names. Experiment $2(\mathrm{~N}=100)$ studied the affect heuristic. The same music excerpts were presented with positive (e.g., Kiss), negative (e.g., Suicide), and neutral (e.g., Window) titles. In both studies, aesthetic and value judgements of music were significantly influenced by the linguistic manipulation of the names. Participants in Experiment 1 evaluated the same music more positively when presented with fluent names compared to disfluent names. In Experiment 2, presenting the music with negative titles resulted in the lowest judgements. Moreover, music excerpts presented with neutral and negative titles were remembered significantly more often than positive titles. Finally, a comparison of the music presented with and without titles indicated that music excerpts were more liked in the presence of titles than in their absence. The present research shows different ways in which aesthetic and value judgements can be influenced by the names presented with music. Results suggest that like any other human judgement, evaluations of music also rely on heuristic principles that do not necessarily depend on the aesthetic stimuli themselves.
\end{abstract} Keywords: music evaluation, artist name, title, fluency, affect heuristic 


\section{Names and Titles Matter: The Impact of Linguistic Fluency and the Affect}

\section{Heuristic on Aesthetic and Value Judgements of Music}

The idea is straightforward, as argued by Danto (1981). Imagine an art exhibition where four identical plain red paintings are placed next to each other. The only difference between them is that they are presented with different titles. One painting is called "The Israelites Crossing the Red Sea", another "Kierkegaard's mood". There is also a painting titled "Red Square" and another named "Nirvana". Visitors to this exhibition would perceive and appreciate these identical paintings in different ways, influenced by the titles and resulting in different aesthetic judgements. Danto concluded (1981): "A title is more than a name: frequently it is a direction for interpretation or reading, which may not always be helpful” (p. 3). The influence of titles on art appreciation and evaluation has been largely studied in the world of visual arts, but to the best of our knowledge, there are no studies in the published literature that examined the extent to which titles presented with music impact aesthetic and value judgements. Thus, the present study endeavours to make its contribution by investigating the effects of titles and artist names on the evaluation of music.

Listening to music is a prevalent activity wherein people constantly make decisions and judgements, the results of which are essential in determining individuals' musical preferences and choice behaviour. Ultimately, these pattern of preferences and judgements will underlie a person's musical taste and identity. Researchers have been able to identify a large number of influences that affect people when listening to and evaluating music, suggesting three main interconnected factors: the music, the listener, and the listening context (see Hargreaves, North, \& Tarrant, 2006; LeBlanc, 1982, for theoretical models considering the three factors; see Greasley \& Lamont, 2016; North \& Hargreaves, 2008, for research reviews). The vast majority of studies have focused on 
the music and the listener, examining the effect of musical characteristics (e.g., complexity, familiarity, style, tempo, volume) on judgements and preferences (e.g., Berlyne, 1971; 1974; North \& Hargreaves, 1995, 2000a; Russell, 1986); as well as individual aspects of the listener that influence preferences for music, including age, gender, personal values, cognitive styles, and personality (e.g., Bonneville-Roussy, Rentfrow, Xu, \& Potter, 2013; Greenberg, Baron-Cohen, Stillwell, Kosinski, \& Rentfrow, 2015; Lonsdale \& North, 2011; North \& Hargreaves, 2007; Rentfrow \& Gosling, 2003). Comparatively, less attention has been paid to the listening context, although there are reasons to believe that they play a crucial role in the processes involved in listening to music and evaluation (e.g., Egermann et al., 2011; Greasley \& Lamont, 2011;North \& Hargreaves, 2000b; North, Hargreaves, \& Hargreaves, 2004). Sloboda (1999) stated that listening to music is 'intensely situational' (p. 355), suggesting that the context wherein people listen to music is crucial to understanding musical judgements, preferences, and choice behaviour. In support of this view, studies have identified a number of nonmusical factors, inseparable from the listening situation in the real-world, that affect people when perceiving and evaluating music. Visual information is one of the most salient (see Platz \& Kopiez, 2012, for a review). There is evidence that performer's body movements (e.g., Behne \& Wöllner, 2011; Juchniewicz, 2008;), physical attractiveness (Ryan, Costa-Giomi, 2004; Wapnick , Mazza, \& Darrow, 2000), appropriateness of dress (Griffiths, 2008; Wapnick et al., 2000), and race and gender (Davidson \& Edgar, 2003; Elliot, 1995) are influential in the evaluation of music. Similarly, the explicit or contextual information, which frequently accompanies music, has also been shown to be a relevant factor. Presenting music with different types of explicit information, such as texts, labels, and subtitles, has a significant impact on evaluations of music (Anglada-Tort \& Müllensiefen, 2017; Duerksen, 1972; 
Margulis, 2010; Margulis, Kisida, \& Greene, 2015; Margulis, Levine, Simchy-Gross, \& Kroger, 2017; North \& Hargreaves, 2005; Silveira \& Diaz, 2014; Vuoskoski \& Eerola, 2013). When presented with music, explicit information can intensify the emotionality of the music (Vuoskoski \& Eerola, 2013; Margulis et al., 2017), enhance children's attention and comprehension of music performances (Margulis et al., 2015), and alter listeners' evaluations of music on different dimensions of subjective judgement (e.g., liking, musical quality, pitch and rhythm accuracy) (Anglada-Tort \& Müllensiefen, 2017; Duerksen, 1972).

Since artist names and song titles are a fundamental property of music and a type of explicit information normally presented with music, we deemed that they merit further empirical investigation. Although studies have found that song titles are relatively important in memory and metamemory for music (Barlett \& Snelus, 1980; Korenmann \& Peynircioğlu, 2004; Peynircioğlu, Rabinovitz, \& Thompson, 2008), the question of whether titles and artist names influence people when listening to and evaluating music has not been empirically addressed.

In the world of visual art, however, the influence of titles on the appreciation and evaluation of paintings has been investigated repeatedly. Presenting pieces of art with titles has a significant effect on the understanding and interpretation (Millis, 2001; Leder, Carbon, \& Ripsas, 2006; Russell, 2003; Swami, 2013), visual exploration (Hristova, Georgieva, \& Grinberg, 2011; Kapoula, Daunys, Herbez, \& Yang, 2009), and liking (Belke, Leder, Strobach, \& Carbon, 2010; Gerger \& Leder, 2015; Millis, 2001; Russell, 2003; Swami, 2013) of artworks. Researchers have also looked at the differences between the presence and absence of titles, showing that the same pieces of art are normally rated more favourably when they are presented with titles than in their 
absence (Cleeremans, Ginsburgh, Klein, \& Noury, 2016; Leder, et al., 2006; Millis, 2001).

When manipulating the linguistic properties of names and titles, the present study made use of two heuristic principles that have been shown to play a crucial role in human judgement and decision making, namely processing fluency (see Reber, Schwarz, \& Winkielman, 2004, for a review) and the affect heuristic (see Slovic, Finucane, Peters, \& MacGregor, 2002, for a review). Processing fluency refers to the human tendency to evaluate information that is easy-to-process more positively than similar but more difficult-to-process information. Studies have shown that easy-toprocess stimuli are believed to be more frequent (Tversky \& Kahneman, 1973), true (Reber \& Schwarz, 1999), famous (Jacoby, Kelly, Brown, \& Jascheko, 1989), likeable (Reber, Winkielman, \& Schwarz, 1998), and familiar (Whittlesea \& Williams, 1998) than similar but less-fluent stimuli. Shah \& Oppenheimer (2007) applied the principle of fluency to the evaluation of financial stocks, finding that when stocks were presented with easy-to-pronounce brokerage firm names they were evaluated more positively than when presented with hard to pronounce names. This kind of manipulation is known as linguistic fluency (Alter \& Oppenheimer, 2006; Whittlesea \& Leboe, 2000). One of the motivations of the present paper was to apply the same principle to study the effects of title and artist name on the evaluation of music (Experiment 1).

The affect heuristic refers to the reliance on good and bad feelings associated with a stimulus (Kahneman \& Frederick, 2002; Slovic, Finucane, Peters, \& MacGregor, 2002). Research from psychology, economics, and decision making strongly supports the existence of this heuristic principle, showing that people rely on subjective affective responses when making decisions and judgements (e.g., Finucane, Alhakami, Slovic, \& Johnson, 2000; Hsee \& Rottenstreich, 2004; Loewenstein, Weber, Hsee, \& Welch, 
2001; Pham \& Avnet, 2009; Ratner \& Herbst, 2005; Rottenstreich \& Hsee, 2001). It is worth mentioning that these studies were mainly concerned with judgements of probability, frequency, and risk. Thus, it is difficult to know whether the affect heuristic is an important mechanism underlying aesthetic and musical judgements. However, Margulis et al. (2017) presented ambiguous music with neutral, positive, and negative information and found a significant effect on the perception of the music. The music excerpts were perceived happier when paired with positive information and sadder when paired with negative information.

Song titles play an important role in everyday music listening behaviour. Titles are used when searching for and choosing music, presenting and organising music in playlists, and identifying as well as remembering our favourite tunes. In some cases, song titles suggest positive or negative emotional content (e.g., 'Tragedy' by Norah Jones, or 'Kiss' by Prince). Research in psycholinguistics has demonstrated that the emotional content of words plays a crucial role in language processing (e.g., Blanchette \& Richards, 2010; Kissler \& Herbert, 2013), suggesting that emotional words (e.g., love or death) are processed differently than neutral words (e.g., table). Importantly, emotional words have been repeatedly demonstrated as being better remembered than neutral words (e.g., Ferré. 2003; Ferré, Sánchez-Casas, \& Fraga, 2013; Herbert, Junghofer, \& Kissler, 2008; Kensinger, 2008; Talmi, Schimmack, Paterson, \& Moscovitch, 2007). Furthermore, the processing of emotional words might be different in the two languages of bilingual speakers and modulated by language proficiency (Farré, Anglada-Tort, \& Guasch, 2017). Thus, we were interested in studying the effects of title emotionality on music evaluation and memory, using both a sample of native English speakers and a sample of bilinguals whose second language was English (Experiment 2). 
The main aim of the present research was to investigate to what extent names presented with music have an impact on aesthetic and value judgements of music. In Experiment 1, we manipulated the linguistic fluency of titles and artist names.

According to the principle of processing fluency, we hypothesized that the same music pieces would be evaluated more positively when presented with easy-to-pronounce names (fluent) than when presented with difficult-to-pronounce names (disfluent). In Experiment 2, we manipulated the emotional content of titles and created positive, negative, and neutral titles. According to the affect heuristic and findings from psycholinguistics, we hypothesized that musical judgements would be influenced by emotional associations evoked by the titles, although we could not predict in which direction. Moreover, Experiment 2 explored title effects on memory, as well as differences in judgements when the music was presented with and without titles. In the two experiments, we measured participants' levels of music training. In experiment 2, we also examined whether different levels of English proficiency would be associated with title effects. Ultimately, when studying participants' responses to music, we measured two distinct evaluative dimensions: aesthetic properties of the music and subjective value of the music.

\section{Experiment 1}

Experiment 1 investigated whether aesthetic and value judgements of popular music can be influenced simply by presenting the music with names differing in their linguistic fluency. English native speakers listened to and evaluated music excerpts presented with different Turkish names. In the fluent condition, titles and artist names were easy-to-pronounce (e.g., Dermod by Artan), whereas in the disfluent condition the names were difficult-to-pronounce (e.g., Taahhut by Aklale). Participants' levels of music training were also taken into consideration. The experiment was based on a 
previous study that investigated the effects of linguistic fluency on the evaluation of financial stocks (Shah \& Oppenheimer, 2007).

\section{Method}

\section{Participants}

A sample of 48 participants (25 male, 23 female), aged 18-32 $(M=24.23, S D=$ 3.12) took part in the experiment. All participants were native English speakers and did not speak a second language fluently. Twenty-five participants were highly trained musicians $(M=46.08, S D=4.91$ in the Gold-MSI Music Training factor; Müllensiefen, Gingras, Musil, \& Stewart, 2014), corresponding to the $98^{\text {th }}$ percentile of the data norm reported in Müllensiefen et al. (2014). Twenty-three participants had low levels of music training $(M=23.6, S D=8.59$ in the Gold-MSI Music Training factor), corresponding to the $38^{\text {th }}$ percentile. Participants were university students at Goldsmiths, University of London. Participation was on a volunteer basis.

\section{Design}

The study employed a mixed within- and between-participants design. The linguistic fluency of the names (fluent vs. disfluent) was measured within-participants (each participant was presented with eight music excerpts, paired with four fluent and four disfluent names) and between-participants (each music excerpt was presented with one fluent and one disfluent name across participants). The eight music excerpts were randomly divided into two sets (Set $A$ and $\operatorname{Set} B$ ). Each music excerpt was randomly paired with one fluent and one disfluent pair of names, containing both the name of the artist and the title of the piece. In group 1, set A was presented with the fluent names and set B with the disfluent names; in group 2, set A was presented with the disfluent names and set B with the fluent names. The experiment had two parts, each part contained two music excerpts from set A with fluent names and two from set B with 
disfluent names. The order of presentation of the music excerpts was fully counterbalanced across participants in each part. In the two groups, half of the participants started with part 1 and the other half with part 2.

\section{Materials}

Music stimuli. $\quad$ Eight music excerpts were selected from a pool of unfamiliar music excerpts that had not been publically released (Rentfrow, Goldberg, \& Levitin, 2011). To make sure that the music exemplars were unknown but had a similar style and quality to representative hits, Rentfrow et al. (2011) used a two-step procedure: they first consulted professionals (i.e., musicologists and recording industry professionals) to identify representative pieces for a number of sub-genres. The professionals were instructed to select major-record-label music that had been commercially released, but that obtained low results in sales. This music pieces had been subjected to the many steps prior to commercialization, but they were not commercially successful. Thus, it was unlikely to have been heard previously by many people. In the next step, the authors reduced the number of selected exemplars by collecting validation data from a pilot sample of 500 listeners. Using the results of this pilot study, the authors chose the music pieces that were evaluated as the most representative of each genre. From this pool of music stimuli, we selected eight excerpts that fell within the same music genre (i.e., rock 'n' roll) and were similar in style. The eight music excerpts had a length of 15 seconds each and did not contain vocals.

Fluent and disfluent names. Using English names would involve confounding variables such as meaning and familiarity, which would make it difficult to measure only the effects of fluency. Moreover, using disfluent names in English could reflect negatively on a particular artist or music piece, implying poor marketing or managing strategies. To avoid this problem, we told participants that they were rating Turkish 
music and used Turkish names that were shown in a previous study to be fluent or disfluent (Shah \& Oppenheimer, 2007). In this previous study, 31 participants were asked to evaluate how easy it would be to pronounce different names on a scale of 1 (very easy) to 10 (very difficult). From 175 tested names, the eight most fluent names $(M=2.74, S E=.03)$ and the eight most disfluent $(M=6.87, S E=.15)$ were selected We adapted these names to create four pairs of fluent and four pairs of disfluent Turkish titles and artist names (see Table 1 for a list of the names used). Using Turkish names not only allowed the control of a number of confounding variables, but it also helped to make the manipulation of linguistic fluency less obvious. The awareness of the fluency manipulation should be lower when using Turkish than when using English names, especially if the sample of participants are monolingual English speakers.

Insert Table 1 here.

Evaluation form. Participants evaluated each music excerpt using six Likert rating scales. Three rating scales were intended to measure aesthetic properties of the music: (1) liking of the music, on a scale from 1 (dislike strongly) to 7 (like strongly), (2) emotional expressivity, on a scale from 1 (very bad) to 7 (very good), (3) musical quality, on a scale from 1 (very bad) to 7 (very good), whereas the other three were intended to measure the subjective value of the music: (4) how likely the "song" would succeed commercially, (5) how likely participants would be to attend a concert of the artist, and (6) how likely participants would be to recommend the "song" to a friend, on a scale from 1 (very unlikely) to 7 (very likely). Cronbach's alphas for the three rating scales measuring aesthetic properties of the music and the three rating scales measuring the subjective value of the music were .84 and .82 , respectively 
At the end of the experiment, several questions were provided to assess whether participants were native English speakers and spoke a second language. Finally, participants were asked whether they thought that they were affected by the names presented with the music, on a scale from 1 (not at all) to 5 (always).

\section{Procedure}

Participants were tested individually in a cubicle room $(150 \mathrm{~cm} \times 200 \mathrm{~cm})$ and sat in front of a computer located approximately $60-70 \mathrm{~cm}$ to them. The music excerpts were presented via professional headphones (KNS 8400 Studio Headphones KRK). Participants were told that the main purpose of the study was to examine how people evaluate music made by Turkish amateur musicians. First, participants filled out the Gold-MSI questionnaire. Then, participants were instructed to listen to the music excerpts and evaluate them as accurately as possible. The experiment had two parts with exactly the same procedure. In each part, participants listened to four music excerpts, two with fluent names and two with diffluent names. At the end of each part, participants had to fill the final evaluation form. The experiment was constructed on Qualtrics software (Qualtrics, Provo, UT). The experiment was granted ethical clearance by the Ethics Committee of the Department of Psychology of Goldsmiths College, University of London.

\section{Statistical Analysis}

To test the main hypothesis regarding the effects of linguistic fluency, we used the R packages lme4 (Bates, Mächler, Bolker, \& Walker, 2015), AICcmodavg (Mazerolle, 2011), and lmerTest (Kuznetsova, Brockhoff, \& Christensen, 2016) to perform a linear mixed-effects analysis with participants' ratings as the dependent variable. Fluency (fluent and disfluent names) was the fixed independent factor. For selecting the random effect structure, we followed a strategy based on the corrected 
Akaike Information Criterion (AICc) and the Bayesian Information Criterion (BIC). We specified three different models with the same fixed effect structure but with (1) random intercept for participants only, (2) random intercepts for participants and music excerpts, and (3) random intercepts for participants, music excerpts, and a random slope for fluency affecting participants. Model 2 achieved the smallest AIC and BIC values and hence we chose the random effect structure to indicate random intercepts for participants and music excerpts.

\section{Results}

A principal component analysis (PCA) was conducted on the six rating scales. The Kaiser-Meyer-Olkin (KMO) measure verified the sampling adequacy for the analysis, $\mathrm{KMO}=.84$ (values between .8 and .9 are considered 'great' according to Hutcheson \& Sofroniou, 1999), and all KMO values for the individual rating scales were greater than .62 , which is above the commonly accepted limit of .5. Barlett's test of sphericity $X^{2}(15)=1401.27, p<.001$, indicated that correlations between items were sufficiently large for PCA. The scree plot was very clear and indicated a solution with just one component. A single component had an eigenvalue of 3.85 which is above Kaiser' criterion of 1 and explained $64.26 \%$ of the variance. Thus, the PCA clearly indicated a model with a single component only (loading of the six rating scales on the single component are given in Appendix A). Participants' ratings on the six Likert scales were aggregated into a single score by averaging the six rating scales for each participant.

The linear mixed-effect model with the fluency of names as the fixed factor and the single aggregated component as the dependent variable revealed a significant main effect of linguistic fluency $(p<.05$; see Appendix B for the summary table of the model). Figure 1 shows the effect of fluency on each of the six rating scales. 
Participants evaluated the music excerpts more positively when presented with fluent names $(M=4.42, S D=1.05)$ than when presented with disfluent names $(M=4.24, S D=$ 1.06). The marginal $\mathrm{R}^{2}$ of the model (variance explained by the fixed factor) was .006 and the conditional $\mathrm{R}^{2}$ of the model (variance explained by both fixed and random factors) was .429 .

Insert Figure 1 here.

To investigate whether participants with higher levels of music training were differently affected by the fluency of names than participants with low levels of music training, we repeated the same analysis adding music training self-report score and the interaction of music training with fluency as fixed factors. The model indicated that the music training main effect and the interaction were statistically not significant $(p>.05)$.

Finally, when participants were asked whether they thought that they were affected by the names presented with the music, on a scale from 1 (not at all) to 5 (always), participants' mean score was $1.25(S D=.44)$. In this question, 93.8\% participants thought that they were 'not at all' $(77.1 \%)$ or 'rarely' $(16.7 \%)$ affected by the names presented with the music.

\section{Discussion}

Experiment 1 showed that the linguistic fluency of names presented with popular music had a significant impact on aesthetic and value judgements. The same music excerpts were evaluated more positively when presented with easy-to-pronounce names (fluent) than when presented with difficult-to-pronounce names (disfluent). This finding is in line with research on processing fluency, indicating that fluency gives rise 
to feelings of familiarity and a positive affective response that results in higher judgements of preference (see Reber, Schwarz, \& Winkielman, 2004, for an overview). Experiment 1 was based on a previous study that examined the effects of linguistic fluency on the evaluation of financial stocks (Shah \& Oppenheimer, 2007). We used the same pairs of fluent-disfluent names, but in our experiment participants evaluated aesthetic stimuli (i.e., pieces of music) instead of financial stocks. Results suggest that linguistic fluency affects human judgements regardless of the object that is being evaluated (financial stocks or music).

Interestingly, those participants considered as highly trained musicians were similarly affected by linguistic fluency compared to those participants with lower levels of music training. Moreover, almost all participants (94\%) thought that they were not influenced at all, or rarely, by the presence of names, suggesting that the effect of fluency was unconscious.

Nevertheless, Experiment 1 presented three limitations: (i) the design employed only allowed the presentation of each music excerpt with one fluent and one disfluent pair of names and titles, (ii) we did not run an a-priori power analysis, and (iii) it was not possible to analyse the effect of titles and artist names separately because they were always presented together in a fixed combination.

Having established the importance of linguistic fluency on the evaluation of music, Experiment 2 was designed to overcome the limitations of Experiment 1 and used a different heuristic principle considered to be crucial in human judgement and decision making, namely, the affect heuristic (Slovic et al., 2002).

\section{Experiment 2}

Experiment 2 examined whether aesthetic and value judgements of popular music can be manipulated by presenting music pieces with titles differing in their 
emotional content. English native speakers and bilinguals, whose second language was English, listened to and evaluated music excerpts presented with positive (e.g., Kiss), negative (e.g., Suicide), and neutral (e.g., Sphere) titles. Levels of music training and English proficiency were measured to study possible associations with title effects. At the end of the experiment, an unexpected free recall task asked participants to write down as many music pieces as they could remember. In addition, using music stimuli and data from the ABC_DJ project (Herzog, Lepa, Egermann, Steffens, \& Schönrock, 2017), we were able to compare musical judgements when the music stimuli were presented with and without titles.

\section{Method}

\section{Participants}

A sample of 100 participants (66 male, 34 female), aged 21 to 37 ( $M=27.66, S D$ $=3.52)$ took part in the experiment. Twenty-seven participants were native English speakers and 73 were bilinguals who spoke English as a second language. Bilinguals' level of English was fairly good $(M=5.85, S D=.80$, on a 7-point self-assessment scale, where 1 was 'very poor' and 7 was 'native-like'). Participants' mean score in the GoldMSI music training factor (Müllensiefen et al., 2014) was $26.47(S D=5.87)$, which indicates an overall average level of music training, corresponding to the $47^{\text {th }}$ percentile of the data norm reported in Müllensiefen et al. (2014). While 23 Participants were tested under lab conditions, the remaining 77 were tested online. Participants were recruited via social media as well as at Goldsmiths, University of London and Technische Universität Berlin. Participation was on a volunteer basis.

An a-priori power analysis using a F-test for mixed within- and betweenparticipants designs, with three between factors (positive, negative, and neutral titles) and nine within factors (the nine music excerpts), indicated that a sample size of at least 
90 participants would be required to detect a significant main effect of titles. The effect size was set to .25 , and the significance level $\alpha$ and the power $1-\beta$ were set to .05 and .80 , respectively. The power analysis was conducted using G*Power (Faul, Erdfelder, Lang, \& Buchner, 2007).

\section{Design}

The present study employed a mixed within- and between-participants design. The effect of the emotionality of titles was measured within participants (each participant was presented with the nine music excerpts and the nine titles) and betweenparticipants (each music excerpt was presented with the nine titles across participants). The nine titles ( 3 positive, 3 negative, and 3 neutral) were paired with the nine music excerpts using a randomized Latin Square design, which led to a total of nine possible combinations of titles and music excerpts. Nine surveys were created according to the outcome of the Latin Square. The order of presentation of the music excerpts was randomized for each participant. The dependent variables were obtained from 11 rating scales that participants were prompted with after each music excerpt. In addition, an unexpected free recall task was included at the end of the experiment.

\section{Materials}

Music stimuli. $\quad$ Nine music excerpts were selected from a pool of 183 music excerpts created by the ABC_DJ project (Herzog et al., 2017), where 3.485 participants evaluated the music excerpts using 51 semantic attributes (e.g., beautiful, inspiring, authentic, happy). Participants were asked to evaluate how well each semantic attribute fit the music excerpt, from 1 (very bad fit) to 6 (very good fit). In addition, participants also provided liking and familiarity ratings, from 1 (not liked/ familiar at all) to 6 (very much liked/ familiar). The 183 music pieces in the selection pool stemmed from 10 different major genres that had been evaluated by an expert. Each 
music piece was digitally cut into 30 -second-long excerpts (comprising $1^{\text {st }}$ verse and chorus). We selected 16 excerpts that did not contain vocals and fell within the same music genre (i.e., dance and electronic music). Finally, the authors selected the nine songs that were the most similar in style, had the lowest scores on familiarity, and were similar in liking. The nine music stimuli were also selected to be similar in the semantical attributes 'beautiful', inspiring', 'happy', and 'authentic'. The scores of the nine selected music excerpts on these evaluative dimensions are displayed in Appendix C.

Titles A pool of 144 words (48 positive, 48 negative, and 48 neutral) were selected from a previous study (Ferré, Anglada-Tort, \& Guasch, 2017). From the affective norms for English words (ANEW) database (Bradley \& Lang, 1999) we obtained values for valence (rated on a 9-point scale where 1 was 'very negative' and 9= 'very positive') and arousal (rated on a 9-point scale where 1 was 'non-arousing' and 9 was 'very arousing'). To control for confounding aspects routinely considered in psycholinguistic research we matched the selected word on word frequency, length, and concreteness. Frequencies (relative frequency and log frequency), as well as values for length, were obtained from NIM, a search engine designed to provide psycholinguistic research materials (Guasch, Boada, Ferré, \& Sánchez-Casas, 2012). Concreteness values were obtained from Brysbaert, Warriner, and Kuperman (2014), a normative study in which 37,059 English words were rated on a 5-point scale (1= very abstract; 5= very concrete). In addition, we aimed to control for the plausibility of the words to serve as titles of music pieces by presenting 24 words ( 8 positive, 8 negative, and 8 neutral) to a separate sample of 25 participants. In this pre-test, participants were asked to rate whether the words could serve as the title of a piece of music on a 5-point scale $(1=$ not at all, 5= very much). 
Table 2 shows the nine words ( 3 positive, 3 negative, and 3 neutral) selected to be the titles, according to the following criteria: In the valence dimension, positive, negative, and neutral words should be significantly different (positive $>$ negative $>$ neutral). In the arousal dimension, positive and negative words should be equal and significantly different compared to neutral words (positive $=$ negative $>$ neutral). On the remaining dimensions, the nine words should not differ significantly. In addition, positive and negative words should be similarly extreme with regard to valence compared to neutral words. Valence magnitude was calculated by subtracting valence scores to the mid-point scale ' 5 ' (e.g., a valence of 7 results in a valence magnitude of 2).

The affective, semantic, and lexical characteristics of the 9 words selected to be the titles are displayed in Appendix D. A one-way ANOVA with emotional content (positive, negative, and neutral words) as the between-group factor was used to check that conditions differed in the manipulated variables. This analysis revealed that positive, negative, and neutral words were significantly different in valence, $F(2,8)=$ $315.78, p<.001, \omega^{2}=.98$; valence magnitude, $F(2,8)=80.68, p<.001, \omega=.62$; and arousal, $F(2,8)=16.01, p=.004, \omega^{2}=.91$. No other variables showed statistical differences among conditions (all $p$-values $>.05$ ). The analysis also showed that negative and positive words did not differ significantly in arousal and valence magnitude $(p$-values $>.05)$.

Insert Table 2 here.

Evaluation form. Participants evaluated each music excerpt using 11 Likert rating scales, which were used to measure different dimensions of music evaluation and 
appreciation. Five rating scales were selected from a previous study (Herzog et al., 2017) where participants evaluated the same music excerpts presented without titles. These rating scales consisted in (1) liking of the music, on a scale from 1 (not at all) to 6 (very much), and the evaluation of how well different positive attributes fitted the music excerpt, namely, (2) 'Beautiful', (3) 'Happy', (4) 'Inspiring', and (5) 'Authentic', on a scale from 1 (very bad fit) to 6 (very good fit). We selected these five rating scales to measure different aspects of the aesthetic value of the music, as well as to enable the comparison of music evaluations in the presence and absence of titles. Cronbach's alpha for these five rating scales was .87 .

In addition, we created two sets of ratings designed to measure different aspects of the subjective value of the music. A set of three rating scales was used to measure personal value. Participants had to evaluate the degree of agreement to three statements: (6) "I want to find out more about the artist of the song", (7) "I would share the song with my friends", and (8) "I want to see the artist of the song play live", on a scale from 1 (strongly disagree) to 7 (strongly agree). The second set of three ratings was designed to measure estimated commercial value, using the same agreement-disagreement 7 point scale. Participants had to rate the degree of agreement to three statements: (9) "The song has the potential to succeed commercially", (10) "I think the song comes from a successful artist", (11) "I think many people would like the song”. Cronbach's alphas for the three rating scales measuring personal value and the three rating scales measuring commercial value were .91 and .87 , respectively.

At the end of the experiment, participants were provided with an open-text box and asked the following: "write down all songs that you can remember in any order and separated by commas. Do not worry if you cannot remember any, then just leave the box blank". This unexpected free recall task was used to measure the effect of the 
emotionality of titles on memory. At the end of the experiment, participants were asked whether they thought that they were affected by the names presented with the music, on a scale from 1 (not at all) to 5 (always).

\section{Procedure}

Participants were tested using Qualtrics software (Qualtrics, Provo, UT). The use of headphones was mandatory. Participants were told that the main purpose of the study was to investigate how people evaluate music. After reading the instructions, they were presented with the nine music excepts consecutively. For each music excerpt, participants were first asked to listen the "song" and answer whether they had heard it before. If they answered yes, they skipped the music excerpt and were directed to the next one. Secondly, participants were presented with the music excerpt and its title. To ensure that participants read the title, they were asked to write the title into a text box. Then, participants were provided with the 11 rating scales. Participants could listen to the music excerpts as many times as they wanted. On the evaluation form, each music excerpt was presented with its corresponding title on top and in bold type. After repeating the same procedure with the nine music excerpts, participants were asked to fill out the Gold-MSI questionnaire asking about their music training (Müllensiefen et al., 2014) and the energetic and rhythmic factor of the Short Test of Music preferences (STOMP; Rentfrow \& Gosling, 2003), which included preference for dance and electronic music. At the end of the experiment, participants were presented with an unexpected free recall task and the rating scale asking to what extent they thought they were affected by the titles. The experiment was granted ethical clearance by the Ethics Committee of the Technische Universität Berlin, Germany. 


\section{Statistical Analysis}

Title Effects on Aesthetic and Value Judgements. To investigate the effect of the emotionality of titles on evaluations of music, we followed a very similar analysis strategy as in Experiment 1, using linear mixed-effect models. Three mixed-effect models were computed using aesthetic value, personal value, and commercial value as dependent variables. In all analyses, the emotional category of the title (positive, negative, and neutral) was the fixed independent factor. Similar to Experiment 1, we used the corrected Akaike Information Criterion (AICc) and the Bayesian Information Criterion (BIC) to select the random effect structure. We specified four different models with (1) random intercept for participants only, (2) random intercepts for participants and music excerpts, (3) random intercepts for participants, music excerpt, and title, and (4) random intercepts for participants, music excerpt, and random slope for the emotional category of the titles affecting participants. In all analyses, model 2 achieved the smallest AICc and BIC values and we, therefore, chose the random effect structure to indicate random intercepts for participants and music excerpts.

Title Effects on Memory. To analyse the effect of titles on memory, we carried out a linear mixed-effect model using the number of remembered titles as the dependent variable. The emotionality of the remembered titles (positive, negative, or neutral) was the fixed factor and participants was the random effect factor.

Title Effects and Individual Difference Factors. In a subsequent exploratory step, we investigated whether several individual difference factors, which could be acting as moderating or confounding variables, contributed to the effect of titles. Separate linear mixed-effect models were conducted for each individual difference factor, using two dependent variables: aesthetic value and number of remembered titles. In all analyses, the emotional category of the title (positive, negative, and neutral), the 
specific individual difference factor, and their interaction served as fixed factors. We examined participants' levels of English, music training, the STOMP preference factor for energetic and rhythmic music (including dance and electronic music), and testing conditions (i.e., whether participants were tested online or under laboratory conditions).

Titles versus Non-titles. To study differences on the evaluation of popular music when the music was presented with and without titles, we created a dataset comprising the data from the ABC_DJ project (Herzog et al., 2017; where the same music excerpts had been evaluated without titles) and the present study. Participants in the two studies used the same five rating scales to evaluate the music (like, beautiful, happy, inspiring, and authentic). From this previous study (Herzog et al., 2017), where 3.485 participants had evaluated 183 music excerpts, we selected those 597 participants (289 female and 308 male, aged $18-68, M=42.69, S D=13.57$ ) who had evaluated at least one of the nine music excerpts used in the present study. Twenty-eight participants had evaluated two music excerpts, the remaining participants only had given ratings for one of the nine music stimuli. Separate linear mixed-effect models for each individual rating scale as dependent variables were run, resulting in five models. While the title condition (non-title, positive, negative, and neutral titles) was the fixed effect factor, participants and music excerpts were the random effect factors The non-title condition was used as the reference level. Additionally, we employed a model-based confidence interval. Thus, $95 \%$ confidence intervals around the estimates of the fixed effects coefficients were extracted from the linear mixed-effect models using the likelihood profile method. The model-based CIs are useful to determine whether there were significant differences between the three title conditions and the non-title condition. 


\section{Results}

Seven participants who did not complete the online test and two participants who took longer than three hours to complete it were excluded from the analysis.

\section{Title Effects on Aesthetic Value}

The five rating scales measuring aesthetic properties of the music showed great sampling adequacy $(\mathrm{KMO}=.86$ and all $\mathrm{KMO}$ values for individual ratings were $>.83$; Barlett's test of sphericity $\left.X^{2}(10)=2042.97, p<.001\right)$. A single component had an eigenvalue of 3.33 , which is above Kaiser's criterion of 1 , and explained $66.66 \%$ of the variance. The scree plot was clear and indicated a solution with one component (loadings of the three rating scales on the single component solution are given in Appendix E). The five rating scales were averaged per participant to form a single component score for aesthetic value.

The linear mixed-effect model regarding aesthetic value showed a main significant effect of the emotionality of titles $(p<.05$; see a summary table of the model in Appendix F). The marginal $\mathrm{R}^{2}$ (variance explained by the fixed factor) was .006 and the conditional $\mathrm{R}^{2}$ (variance explained by both fixed and random factors) was .334 . As visible in Figure 2, the music excerpts were evaluated significantly lower when presented with negative titles than when presented with neutral titles $(p<.01)$. Although the difference between negative and positive titles was not significant, music excerpts presented with positive titles scored higher on aesthetic value than when they were presented with negative titles.

\section{Title Effects on Personal Value}

The three rating scales measuring personal value indicated good sampling adequacy $(\mathrm{KMO}=.76$ and all $\mathrm{KMO}$ values for individual ratings were $>.75$; Barlett's test of sphericity $\left.X^{2}(3)=1474.94, p<.001\right)$. A single component had an eigenvalue of 
2.56 and explained $85.34 \%$ of the variance. The scree plot was clear and indicated a solution with one component (loadings of the three rating scales on the single component are given in Appendix E). The three rating scales were averaged per participant to form a single component score for personal value.

The linear mixed-effect model predicting personal value did not reveal any main significant effect of the emotionality of titles (see a summary table of the model in Appendix F); the marginal $\mathrm{R}^{2}$ was 0.002 and the conditional $\mathrm{R}^{2}$ was 0.27 . Nevertheless, the direction of the results was consistent with the other analyses (Figure 2), where negative titles led to the lowest ratings and neutral titles to the highest.

\section{Title Effects on Commercial Value}

The three ratings measuring commercial value showed good sampling adequacy $(\mathrm{KMO}=.72$ and all $\mathrm{KMO}$ values for individual ratings were $>.68$; Barlett's test of sphericity $\left.X^{2}(3)=1116.8, p<.001\right)$. A single component had an eigenvalue of 2.37 and explained $78.97 \%$ of the variance. The scree plot was clear and indicated a solution with one component (loadings of the three rating scales on the single component solution are given in Appendix E). Thus, the three rating scales were averaged per participant to form a single component score for estimated commercial value.

The linear mixed-effect model predicting the commercial value showed a significant main significant effect of the emotionality of titles $(p<.05$; see a summary table of the model in Appendix F). The marginal and conditional $\mathrm{R}^{2}$ were .005 and .341 respectively. As visible in Figure 2, participants evaluated the music significantly lower in commercial value when presented with negative titles than when presented with neutral titles $(p<.01)$. Although the difference between negative and positive titles was not significant, when music excerpts were presented with positive titles they scored higher on commercial value than when presented with negative titles. 
Insert Figure 2 here.

\section{Title Effects on Memory}

The linear mixed-effect model with the number of remembered titles as the dependent variable showed a significant main effect of the emotionality of titles ( $p<$ .001 ; see a summary table of the model in Appendix F). The marginal and conditional $\mathrm{R}^{2}$ of this model were .056 and .302 , respectively. As visible in Figure 3, people remembered significantly fewer titles when they were presented with positive titles compared to negative and neutral titles (all p-values $<.001$ ). The title 'Champion' was the least remembered (16 out of 91 participants), whereas the title 'Murderer' was the most remembered (57 out of 91 participants ).

Insert Figure 3 here.

\section{Title Effects and Individual Differences}

The linear mixed-effect models with the individual difference factors of English proficiency, testing conditions, and music training did not reveal any significant effects or interactions. However, in the two models (aesthetic judgements and number of remembered titles), the STOMP preference factor for energetic and rhythmic music was statistically significant ( $p<.05$ in both models). The interaction between the STOMP factor and the emotionality of the title was not significant, therefore, we rerun the two models without interaction (see a summary table of the models in Appendix G). The significant main effect of the STOMP factor indicated that participants with a higher preference for energetic and rhythmic music (including dance and electronic music) 
evaluated the music more positively and remembered more titles than those with a lower preference for this music style.

At the end of the experiment, participants were asked whether they thought that they were affected by the names presented with the music excerpts, on a scale from 1 (not at all) to 5 (always). The mean score of the 91 participants who had completed the experiment was $1.98(S D=.97)$. In this question, $68.13 \%$ participants answered that they were 'not at all' $(40.66 \%)$ or 'rarely' $(27.47 \%)$ affected by the presence of titles.

\section{Titles versus Non-Titles}

The linear mixed-effect models with the five rating scales are summarised in Appendix H. Figure 4 shows the outcome of the five linear mixed-effect models with the model-based CIs (95\%) around the fixed effects. The linear mixed-effect model with the dependent variable 'like' revealed a significant main effect of titles $(\mathrm{p}<.001)$. The model-based CI showed that the same music excerpts were significantly less liked when presented without titles than when presented with titles, regardless of the emotional content of the title. The mixed-effect model with the dependent variable 'inspiring' also indicated a main effect of titles $(p<.05)$. The model-based CI revealed that the same music excerpts were evaluated significantly less inspiring when presented without titles than in the presence of a title, although this difference was only significant when the non-title condition was compared with the neutral title group. Finally, the linear mixedeffect model with the dependent variable 'beautiful' showed a significant effect of titles $(p<.05)$, although the model-based CI did not show any significant differences. This is probably because CIs were created using the likelihood profile method, which is considered more accurate and conservative compared to the Wald method used in the calculation of p-values in lmerTest (Kuznetsova et al., 2016). The models with the dependent variables 'happy' and 'authentic' were nonsignificant ( $p$-values $>.05$ ). 
Because the two samples of participants compared in this analysis were different in age range, we carried out an exploratory analysis to examine whether age was a significant factor. We repeated the same linear mixed-effect models adding age, title conditions, and the interaction between them as a fixed effect factors. Age and the titleage interaction were nonsignificant $(p$-values $>.05)$.

Insert Figure 4 here.

\section{Discussion}

The results of Experiment 2 demonstrate that the emotional content of titles influences aesthetic and value judgements of music. The titles also had a significant impact on participants' memory for music. These findings support the existence of an affect heuristic making (Kahneman \& Frederick, 2002; Slovic et al., 2002) in aesthetic and music evaluations, in which emotional associations evoked by titles can influence listeners' judgements and decisions.

Three different evaluative dimensions were measured: aesthetic value (e.g., liking or beautiful), estimated commercial value (e.g., I think many people would like this "song"), and personal value (e.g., I would share this "song" with my friends). Title effects were clear in the first two dimensions but did not have a significant impact on personal value. This suggests that the personal value of music may be more robust to the effects of titles and cognitive heuristics than other evaluative dimensions. It also provides some evidence for separating the two forms of the subjective value of music assessed in the study: a more personal dimension wherein people evaluate the individual satisfaction received from listening to the music and a more social dimension where the degree in which the music will be enjoyed by others is evaluated. 
However, the interpretation of the direction and strength of the effect associated with the emotional content of titles is not simple: music is not necessarily influenced more positively by positive titles. In fact, participants gave the highest ratings when the music was presented with neutral titles. Arguably, these results could be justified by an interaction between the emotional content of the titles and the emotional content of the music, resulting in congruent and incongruent music-title pairs. An incongruent situation could arise from those cases where positively charged music was paired with a negative title or vice versa, resulting in negative judgements. Since neutral titles lacked emotional content, their combination with the music excerpts was mostly congruent, resulting in more positive judgements, regardless of the emotionality of the music. This hypothetical explanation is in line with a recent study by Margulis et al. (2017), who presented ambiguous music (i.e., music excerpts that could be perceived as positive or negative) with positive, negative, and neutral information. The authors found that ambiguous music was evaluated happier when presented with positive information and sadder when presented with negative information, suggesting that the emotional content of the music is key to determine the direction of the effects caused by the emotionality of the information. Moreover, in a study of art appreciation, Belke et al. (2010) found that titles related to the painting (congruent) were more liked than unrelated titles (incongruent). Importantly, the authors found that the effect of titles (whether they were related or unrelated) was moderated by the content of the paintings, in particular, by the degree of abstraction of the artworks, which lends some plausibility to our congruency hypothesis.

In an unexpected free recall task, music excerpts presented with neutral and negative titles were remembered significantly more often than positive titles. The title 'murderer', for instance, was remembered three times more frequently than the title 
'champion'. This result was unexpected, as it contradicts previous findings from the field of psycholinguistics, where researchers have found repeatedly a superiority for emotional words (positive and negative) over neutral words in memory (e.g., Ferré, 2003; Ferré et al., 2013; Herbert et al., 2008; Kensinger, 2008; Talami et al., 2007). This finding indicates that the interaction between the emotional content of titles and music is important to understand the effect of titles on music evaluation and memory.

Native English speakers and bilingual speakers were similarly influenced by titles. This result could be due to the sample of bilingual speakers used in this experiment, which was fairly proficient in their second language (English). Nevertheless, it is important to mention that in our sample of participants, there were twice as many bilinguals as native speakers. Future research should use a more balanced design in order to measure more accurately whether language proficiency may be associated with title effects. Additionally, there is evidence suggesting that the processing of emotional words is similar in the two languages of highly proficient bilingual speakers, but might differ when using a sample of less proficient bilinguals (Ferré et al., 2017). Thus, when studying explicit information we encourage the use of a balanced design as well as bilinguals whose second language is less developed.

Finally, a comparison of the music presented with and without titles revealed that people liked the music significantly more when it was presented with titles than in their absence, regardless of the emotional content of the title. This finding is in line with previous studies showing that the same pieces of art presented with titles are generally evaluated more positively than when presented without titles (Cleeremans et al., 2016; Leder et al., 2006; Millis, 2001). This result is compatible with the 'making meaning brings pleasure' hypothesis, which suggests that titles enhance positive emotional 
responses to art by making art more compressible (Millis, 2001; Russell, 2003; Leder et al., 2006).

\section{General Discussion}

The main aim of the present study was to investigate to what extent names presented with popular music have an impact on aesthetic and value judgements of music. Results from two experiments show the relevance of titles and artist names for the evaluation of music. These findings are in line with evidence for the influence of titles on the evaluation of visual art (e.g., Belke et al., 2010; Millis 2001, Leder et al., 2006; Russell, 2003). To the best of our knowledge, this is the first published study demonstrating that titles and artist names are an important factor for music evaluation.

In Experiment 1, the same music excepts were evaluated more positively when presented with easy-to-pronounce names (fluent) than with difficult-to-pronounce names (disfluent), which is in line with the processing fluency theory (Reber et al., 2004). In Experiment 2, the emotional content of titles not only influenced aesthetic and value judgements, but it also had an impact on participants' memory for music, which supports the existence of an affect heuristic in the evaluation of aesthetic stimuli (Slovic et al., 2002). The results of the two experiments are corroborated by previous research on the influence of contextual and nonmusical factors on music preferences and judgements (see Greasley \& Lamont, 2016; North \& Hargreaves, 2008, for research reviews).

Nevertheless, the relationship between the emotional content of titles and music evaluation is not necessarily simple. The most positive aesthetic and value ratings were found when the same music was presented with neutral titles, and the lowest proportions of remembered music excerpts were found when the music was presented with positive titles. This finding could be due to an interaction of the emotional content 
of the music and the emotionality of the title, resulting in congruent (e.g., positive music excerpts presented with a positive title) and incongruent (e.g., positive music excerpts presented with a negative title) situations. In order to explore this issue further, future research should control for the emotionality of the music in a more sophisticated way as well as assess the perceived congruency or fit between the music piece and the title.

It is important to mention that in the two experiments we only chose music excerpts from the same music genre (rock ' $\mathrm{n}$ ' roll in Experiment 1 and dance/ electronica in Experiment 2). Thus, future research should investigate whether the effects of names presented with music are more or less important for different music styles, as well as further ways in which linguistic properties of the names can be manipulated. It would be also interesting to explore whether the names presented with the music will have a larger effect over time when the perceptual memory for the musical features fades, but the verbal information of the names might still be remembered.

In addition to measuring aesthetics properties of the music, the present research also studied evaluations of the perceived value of the music. In Experiment 2, we were able to distinguish between two types of judgements measuring the subjective value of the music: an evaluative dimension measuring personal satisfaction associated with the music stimuli and a more social dimension measuring the extent to which the music will be enjoyed by others. While the latter was significantly affected by the titles' emotional content, the former was not.

In an attempt to show the relevance of title effects in the real-world, we used four rating scales shown by Egermann, Lepa, Schönrock, Herzog, and Steffens (2017) to be highly relevant for marketing practice. In this study, 305 marketing and audio branding experts were asked to choose from a list of 132 adjectives which they 
considered the most "relevant and important for marketing practice". The attribute 'authentic' was chosen by the $87.54 \%$ (the most frequently chosen), 'inspiring' by $82.30 \%$, 'happy' by $80.98 \%$, and 'beautiful' by $80.33 \%$. Results from Experiment 2 show that some of the most important attributes used by professionals to describe and evaluate music can be easily influenced by the content of titles.

It is important to mention that in the two experiments, the effects of titles and artist names were small in size. This is not surprising given that the music was not manipulated at all and the contextual information manipulated was minimal and could be processed very quickly by participants. The effects of titles on memory were the largest in size found in this study. In addition, participants' levels of music training were not associated with the effects of titles and artist names in any of the two experiments. Interestingly, in Experiment 1 and 2 most participants (94\% and 77\%, respectively) thought that they were not affected at all, or rarely, by the names presented with the music.

Research on behavioural economics and the psychology of decision making has been able to uncover systematic regularities that affect people when making decisions and judgements, known as heuristic principles (see Cartwright, 2014; Hastie \& Dawes, 2010; Kahneman, 2011, for reviews). The study of these heuristic principles has laid the foundations of general psychological principles underlying and determining human judgement and decision making, such as the heuristic-and-biases framework (Kahneman \& Tversky, 1984; Tversky \& Kahneman, 1974) and the adaptive toolbox (Gigerenzer \& Selten, 2002). Although these research frameworks have been highly influential in the fields of psychology, economics, political science and law, they have yet not been applied explicitly to the study of musical aesthetics, judgements, and choice behaviour. Results from the two experiments presented in this paper support the 
idea that like any other human judgement, evaluations of music also rely on cognitive heuristics that do not necessarily depend on the aesthetic stimuli themselves. Therefore, we hope to show potential applications and benefits of using knowledge from behavioural economics and decision making to study judgement and decision processes involving music, an approach we like to term the behavioural economics of music.

The present research shows that when presented with music, names and titles matter, they influence listeners' evaluations of music, resulting in positive or negative judgement biases. Titles can also have an impact on memory. Finally, listeners liked the music significantly more when it was presented with titles than in their absence, regardless of the title's emotional content. Demonstrating the relevance of titles and artist names for the evaluation of music has implications for many areas, including aesthetics, musical judgements and preferences, advertising, marketing, and audio branding. Using concepts from behavioural economics and decision making, we were able to identify two key heuristic principles (i.e., linguistic fluency and the affect heuristic) that play a significant role for music processing and evaluation. We can conclude, rephrasing Danto (1981), that titles and artist names are more than words, they are cues that influence the processes of perceiving and evaluating the music they accompany.

\section{Acknowledgements}

This research has received funding from the European Union's Horizon 2020 research and innovation program under grant agreement No 688122.

\section{References}

Alter, A. L., \& Oppenheimer, D. M. (2006). Predicting short-term stock fluctuations by using processing fluency. Proceedings of the National Academy of Sciences, 103(24), 9369-9372. DOI: 10.1073/pnas.0601071103 
Anglada-Tort, M., \& Müllensiefen, D. (2017). The repeated recording illusion: The effects of extrinsic and individual difference factors on musical judgements. Music Perception, 35(1), 92-115. DOI: 10.1525/mp.2017.35.1.94

Bartlett, J. C., \& Snelus, P. (1980). Lifespan memory for popular songs. The American Journal of Psychology, 93(3), 551. DOI: 10.2307/1422730

Bates, D., Mächler, M., Bolker, B., \& Walker, S. (2015). Fitting linear mixed-effects models using lme4. Journal of Statistical Software, 67(1), 1-48. DOI: 10.18637/jss.v067.i01

Behne, K.-E., \& Wöllner, C. (2011). Seeing or hearing the pianists? A synopsis of an early audiovisual perception experiment and a replication. Musicae Scientiae, 15(3), 324-342. DOI: 10.1177/1029864911410955

Belke, B., Leder, H., Strobach, T., \& Carbon, C. C. (2010). Cognitive fluency: Highlevel processing dynamics in art appreciation. Psychology of Aesthetics, Creativity, and the Arts, 4(4), 214-222. DOI: 10.1037/a0019648

Berlyne, D. E. (1971). Aesthetics and psychobiology. New York, NY: AppletonCentury-Crofts.

Berlyne, D. E. (1974). Studies in the new experimental aesthetics: steps toward an objective psychology of aesthetic appreciation. Oxford, UK: Hemisphere.

Blanchette, I., \& Richards, A. (2010). The influence of affect on higher level cognition: A review of research on interpretation, judgement, decision making and reasoning. Cognition \& Emotion, 24, 561-595.

Bonneville-Roussy, A., Rentfrow, P. J., Xu, M. K., \& Potter, J. (2013). Music through the ages: Trends in musical engagement and preferences from adolescence 
through middle adulthood. Journal of Personality and Social Psychology, 105(4), 703-17. DOI: 10.1037/a0033770

Bradley, M. M., \& Lang, P. P. J. (1999). Affective norms for English words ( ANEW): Instruction manual and affective ratings. Technical Report C-1, The Center for Research in Psychophysiology, University of Florida. DOI: 10.1109/MIC.2008.114

Brysbaert, M., Warriner, A. B., \& Kuperman, V. (2014). Concreteness ratings for 40 thousand generally known English word lemmas. Behavior Research Methods, 46(3), 904-911. DOI: 10.3758/s13428-013-0403-5

Cartwright, E. (2014). Behavioral Economics (2nd Ed.). New York: Routledge.

Cleeremans A., Ginsburgh V., Klein O., Noury A. (2016) What's in a name? The effect of an artist's name on aesthetic judgments. Empirical Studies of the Arts, $34,126-139$.

Danto, A. C. (1981). The transfiguration of the commonplace: A philosophy of the art. Cambridge, MA: Harvard University Press.

Davidson, J. W., \& Edgar, R. (2003). Gender and Race Bias in the Judgement of Western Art Music Performance. Music Education Research, 5(2), 169-181. DOI: $10.1080 / 1461380032000085540$

Duerksen, G. L. (1972). Some effects of expectation on evaluation of recorded musical performance. Journal of Research in Music Education, 20(2), 268-272. DOI: $10.2307 / 3344093$

Egermann, H., Lepa, S., Schönrock, A., Herzog, M., \& Stefenns, J. (2017). Development and evaluation of a General Attribute Inventory for Music in Branding. In J. Ginsborg \& A. Lamont (Eds.), Proceedings of the 25th Anniversary Conference of the European Society for the Cognitive Sciences of Music (ESCOM), 
Ghent, Belgium.

Egermann, H., Sutherland, M. E., Grewe, O., Nagel, F., Kopiez, R., Altenmüller, E., \& Altenmuller, E. (2011). Does music listening in a social context alter experience? A physiological and psychological perspective on emotion. Musicae Scientiae, 15(3), 307-323. DOI: 10.1177/1029864911399497

Elliott, C. A. (1995). Race and gender as factors in judgments of musical performance. Bulletin of the Council for Research in Music Education, 127, 50-56.

Faul, F., Erdfelder, E., Lang, A.-G., \& Buchner, A. (2007). G*Power 3: A flexible statistical power analysis program for the social, behavioral, and biomedical sciences. Behavior Research Methods, 39, 175-191.

Ferré, P. (2003). Effects of level of processing on memory for affectively valenced words. Cognition \& Emotion, 17, 859-880.

Ferré, P., Anglada-Tort., M., Guash, M. (in press, 2017). Processing of emotional words in bilinguals: Testing the effects of words' concreteness, task type, and language status. Second Language Research.

Ferré, P., Fraga, I., Comesaña, M., \& Sánchez-Casas, R. (2015). Memory for emotional words: The role of semantic relatedness, encoding task and affective valence. Cognition and Emotion, 29(8), 1401-1410.

Finucane, M. L., Alhakami, A., Slovic, P., \& Johnson, S. M. (2000). The affect heuristic in judgments of risks and benefits. Journal of Behavioral Decision Making, 13(1), 1. DOI: 10.1002/(SICI)1099-0771(200001/03)13:1<1::AIDBDM333>3.0.CO;2-S

Gerger, G., \& Leder, H. (2015)Titles change the esthetic appreciations of paintings. Frontiers in Human Neuroscience, 9. DOI: 19.3389/fnhum.2015.00464 
Gigerenzer, G., \& Selten, R. (2002). Bounded rationality: The adaptive toolbox. Cambridge, MA: MIT press.

Greasley, A. E., \& Lamont, A. (2011). Exploring engagement with music in everyday life using experience sampling methodology. Musicae Scientiae, 15(1), 45-71. DOI: $10.1177 / 1029864910393417$

Greasley, A., \& Lamont, A. (2016). Musical preferences. In S. Hallam, I. Cross, \& M. Thaut (Eds.), Oxford handbook of music psychology (2nd ed., pp. 263-281). Oxford, UK: Oxford University Press.

Greenberg, D. M., Baron-Cohen, S., Stillwell, D. J., Kosinski, M., \& Rentfrow, P. J. (2015). Musical preferences are linked to cognitive styles. PLoS ONE, 10(7). DOI: 10.1371/journal.pone.0131151

Griffiths, N. K. (2008). The effects of concert dress and physical appearance on perceptions of female solo performers. Musicae Scientiae, 12(2), 273-290. DOI: $10.1177 / 102986490801200205$

Guasch, M., Boada, R., Ferré, P., \& Sanchez-Casas, R. (2013). NIM: A web-based swiss army knife to select stimuli for psycholinguistic studies. Behavior Research Methods, 45, 765-771. DOI: 10.3758/s13428-012-0296-8

Hargreaves, D. J., North, A. C., \& Tarrant, M. (2006). Musical Preference and taste in childhood and adolescence. In the child as musician: A handbook of musical development (pp. 135-154). Oxford, UK: Oxford University.

Hastie, R., \& Dawes, R. M. (2010). Rational Choice in an Uncertain World: The Psychology of Judgement and Decision Making. Thousand Oaks, CA: SAGE Publications.

Herbert, C., Junghofer, M., \& Kissler, J. (2008). Event related potentials to emotional adjectives during reading. Psychophysiology, 45, 487-498. 
Herzog, M., Lepa, S., Egermann, H., Steffens, J., \& Schönrock, A. (2017). Predicting musical meaning in audio branding scenarios. In J. Ginsborg \& A. Lamont (Eds.), Proceedings of the 25th Anniversary Conference of the European Society for the Cognitive Sciences of Music (ESCOM), Ghent, Belgium.

Hristova E., Georgieva S., Grinberg M. (2011). Top-down influences on eyemovements during painting perception: the effect of task and titles. Toward Autonomous, Adaptive, and Context Aware Multimodal Interfaces. Theoretical and Practical Issues (pp. 104-115). DOI: 10.1007/978-3-642-18184-9_10

Hsee, C. K., \& Rottenstreich, Y. (2004). Music, pandas, and muggers: on the affective psychology of value. Journal of Experimental Psychology, 133(1), 23-30. DOI: $10.1037 / 0096-3445.133 .1 .23$

Hutcheson, G. D., \& Sofroniou, N. (1999). The multivariate social scientist. Introductory statistics using generalized linear models. DOI: $10.4135 / 9780857028075$

Jacoby, L. L., Kelley, C., Brown, J., \& Jasechko, J. (1989). Becoming famous overnight: Limits on the ability to avoid unconscious influences of the past. Journal of Personality and Social Psychology, 56(3), 326-338. DOI: $10.1037 / 0022-3514.56 .3 .326$

Juchniewicz, J. (2008). The influence of physical movement on the perception of musical performance. Psychology of Music, 36, 417-427

Kahneman, D. (2011). Thinking, fast and slow. New York: Farrar, Straus and Giroux. Kahneman, D., \& Frederick, S. (2002). Representativeness revisited: Attribute substitution in intuitive judgment. In T. Gilovich, D. Friffin, D. Kahneman (Eds.), Heuristics and biases: The psychology of intuitive thought (pp. 49-81). New York: Cambridge University Press. 
Kahneman, D., \& Tversky, A. (1984). Choices, values, and frames. American psychologist, 39(4), 341. DOI: 10.1037/0003-066X.39.4.341

Kapoula, Z., Daunys, G., Herbez, O., \& Yang, Q. (2009). Effect of title on eyemovement exploration of cubist paintings by Fernand Léger. Perception, 38(4), 479-491. DOI: 10.1068/p6080

Kensinger, E. A. (2008). Age differences in memory for arousing and nonarousing emotional words. The Journals of Gerontology Series B: Psychological Sciences and Social Sciences, 63, 13-18.

Kissler, J., \& Herbert, C. (2013). Emotion, Etmnooi, or Emitoon?-Faster lexical access to emotional than to neutral words during reading. Biological Psychology, 92, 464-479.

Korenman, L. M., \& Peynircioğlu, Z. F. (2004). The role of familiarity in episodic memory and metamemory for music. Journal of Experimental Psychology: Learning, Memory, and Cognition, 30(4), 917-22. DOI: 10.1037/02787393.30.4.917

Kuznetsova, A., Brockhoff, P. B., \& Christensen R. H. B. (2016). lmerTest: Tests for random and fixed effects for linear mixed effect models. $R$ Package Version 2.033. Retrieved from http://CRAN.R-project.org/package=lmerTest

LeBlanc, A. (1982). An interactive theory of music preference. Journal of Music Therapy, 19(1), 28-45.

Leder, H., Carbon, C. C., \& Ripsas, A. L. (2006). Entitling art: Influence of title information on understanding and appreciation of paintings. Acta Psychologica, 121(2), 176-198.DOI: 10.1016/j.actpsy.2005.08.005

Loewenstein, G. F., Weber, E. U., Hsee, C. K., \& Welch, N. (2001). Risks as feelings. Psychological Bulletin. DOI: 10.1037/0033-2909.127.2.267 
Lonsdale, A. J., \& North, A. C. (2011). Why do we listen to music? A uses and gratifications analysis. British Journal of Psychology, 102(1), 108-134. DOI: $10.1348 / 000712610 X 506831$

Margulis, E. H. (2010). When program notes don't help: Music descriptions and enjoyment. Psychology of Music, 38, 285-302.

Margulis, E. H., Kisida, B., \& Greene, J. P. (2015). A knowing ear: The effect of explicit information on children's experience of a musical performance. Psychology of Music, 43(4), 596-605. DOI: $10.1177 / 0305735613510343$

Margulis, E. H., Levine, W. H., Simchy-Gross, R., \& Kroger, C. (2017). Expressive intent, ambiguity, and aesthetic experiences of music and poetry. PloS ONE, 12(7), e0179145. DOI: 10.1371/journal.pone.0179145

Mazerolle, M. J. (2011). AICcmodavg: Model selection and multimodel inference based on (Q) AIC (c). R Package Version, 2.1-1. Retrieved from https://cran.rproject.org/web/packages/AICcmodavg/AICcmodavg.pdf

Millis, K. (2001). Making meaning brings pleasure: The influence of titles on aesthetic experiences. Emotion, 1(3), 320-329.DOI: 10.1037/1528-3542.1.3.320

Müllensiefen, D., Gingras, B., Musil, J., \& Stewart, L. (2014). The musicality of nonmusicians: An index for assessing musical sophistication in the general population. PloS ONE, 9(2), e89642. DOI: 10.1371/journal.pone.0089642

North, A. C., \& Hargreaves, D. J. (1995). Subjective complexity, familiarity and liking for popular music. Psychomusicology, 14(1966), 77-93. DOI: $10.1037 / \mathrm{h} 0094090$

North, A. C. \& Hargreaves, D. J. (2000a). Collative variables versus prototypicality. Empirical Studies of the Arts, 18(1), 13-17. 
North, A. C., \& Hargreaves, D. J. (2005). Brief report: Labelling effects on the perceived deleterious consequences of pop music listening. Journal of adolescence, 28(3), 433-440.

North, A. C., \& Hargreaves, D. J. (2007). Lifestyle correlates of musical preference: 1. Relationships, living arrangements, beliefs, and crime. Psychology of Music, 35(1), 58-87. DOI: 10.1177/0305735607068888

North, A., \& Hargreaves, D. (2008). The social and applied psychology of music. New York, NY: Oxford University Press.

North, A. C., Hargreaves, D. J., \& Hargreaves, J. J. (2004). Uses of Music in Everyday Life. Music Perception: An Interdisciplinary Journal, 22(1), 41-77. DOI: 10.1525/mp.2004.22.1.41

Pham, M. T., \& Avnet, T. (2009). Contingent reliance on the affect heuristic as a function of regulatory focus. Organizational Behavior and Human Decision Processes, 108(2), 267-278. DOI: 10.1016/j.obhdp.2008.10.001

Platz, F., \& Kopiez, R. (2012). When the eye listens: A meta-analysis of how audiovisual presentation enhances the appreciation of music performance. Music Perception, 30(1), 71-83. DOI: 10.1525/mp.2012.30.1.71

Peynircioğlu, Z. F., Rabinovitz, B. E., \& Thompson, J. L. W. (2007). Memory and metamemory for songs: The relative effectiveness of titles, lyrics, and melodies as cues for each other. Psychology of Music, 36, 47-61. DOI: $10.1177 / 0305735607079722$

Ratner, R. K., \& Herbst, K. C. (2005). When good decisions have bad outcomes: The impact of affect on switching behavior. Organizational Behavior and Human Decision Processes, 96(1), 23-37. DOI: 10.1016/j.obhdp.2004.09.003 
Reber, R., Schwarz, N., \& Winkielman, P. (2004). Processing fluency and aesthetic pleasure: Is beauty in the perceiver's processing experience? Personality and Social Psychology Review, 8(4), 364-382. DOI: 10.1207/s15327957pspr0804_3

Reber, R., Winkielman, P., \& Schwarz, N. (1998). Effects of perceptual fluency on affective judgments. Psychological Science, 9(1), 45-48. DOI: 10.1111/14679280.00008

Rentfrow, P. J., Goldberg, L. R., \& Levitin, D. J. (2011). The structure of musical preferences: a five-factor model. Journal of Personality and Social Psychology, 100(6), 1139-57. DOI: 10.1037/a0022406

Rentfrow, P. J., \& Gosling, S. D. (2003). The do re mi's of everyday life: The structure and personality correlates of music preferences. Journal of Personality and Social Psychology, 84(6), 1236-1256. DOI: 10.1037/0022-3514.84.6.1236

Rottenstreich, Y., \& Hsee, C. K. (2001). Money, kisses, and electric shocks: on the affective psychology of risk. Psychological Science, 12(3), 185-190. DOI: $10.1111 / 1467-9280.00334$

Russell, P. A. (1986). Experimental aesthetics of popular music recordings: Pleasingness, familiarity and chart performance. Psychology of Music, 14(1), 3343. DOI: 0305735686141003

Russell, P. A. (2003). Effort after meaning and the hedonic value of paintings. British Journal of Psychology, 94, 99-110. DOI: 10.1348/000712603762842138

Ryan, C., \& Costa-Giomi, E. (2004). Attractiveness bias in the evaluation of young pianists' performances. Journal of Research in Music Education, 52(2), 141. DOI: $10.2307 / 3345436$ 
Shah, A. K., \& Oppenheimer, D. M. (2007). Easy does it: The role of fluency in cue weighting. Judgment and Decision Making, 2(6), 371-379. DOI: $10.1037 / \mathrm{e} 722852011-015$

Silveira, J. M., \& Diaz, F. M. (2014). The effect of subtitles on listeners' perceptions of expressivity. Psychology of Music, 42(2), 233-250.

Sloboda, J. A. (1999). Everyday uses of music listening: A preliminary study. In S. W. Yi (Ed.) Music, mind and science (pp. 354-369). Seoul: Western Music Research Institute.

Slovic, P., Finucane, M., Peters, E., \& MacGregor, D. G. (2002). Rational actors or rational fools: Implications of the affect heuristic for behavioral economics. Journal of Socio-Economics, 31(4), 329-342. DOI: 10.1016/S1053$5357(02) 00174-9$

Swami, V. (2013). Context matters: Investigating the impact of contextual information on aesthetic appreciation of paintings by Max Ernst and Pablo Picasso. Psychology of Aesthetics, Creativity, and the Arts, 7(3), 285-295. DOI: $10.1037 / \mathrm{a} 0030965$

Talmi, D., Schimmack, U., Paterson, T., \& Moscovitch, M. (2007). The role of attention and relatedness in emotionally enhanced memory. Emotion, 7(1), 89.

Tversky, A., \& Kahneman, D. (1973). Availability: A heuristic for judging frequency and probability. Cognitive Psychology, 5(2), 207-232. DOI: 10.1016/00100285(73)90033-9

Tversky, A., \& Kahneman, D. (1974). Judgment under uncertainty: Heuristics and biases. Science, 185(4157), 1124-1131. DOI: 10.1126/science.185.4157.1124 
Vuoskoski, J. K., \& Eerola, T. (2013). Extramusical information contributes to emotions induced by music. Psychology of Music, 43(2), 262-274. DOI: $10.1177 / 0305735613502373$

Wapnick, J., Mazza, J. K., \& Darrow, A. A. (2000). Effects of performer attractiveness, stage behaviour, and dress on evaluation of children's piano performances. Journal of Research in Music Education, 323(4), 323-335. DOI: $10.2307 / 3345367$

Whittlesea, B. W. A., \& Leboe, J. P. (2000). The heuristic basis of remembering and classification: Fluency, generation, and resemblance. Journal of Experimental Psychology. General, 129(1), 84-106. DOI: 10.1037/0096-3445.129.1.84 
Table 1

Fluent and Disfluent Turkish Names

\begin{tabular}{ll}
\hline Fluent & Disfluent \\
\hline Dermod by Artan & Siirt by Lasiea \\
Kado by Pera & Taahhut by Aklale \\
Boya by Tatra & Emniyet by Luici \\
Alet by Ferka & Dizayn by Sampiy \\
\hline
\end{tabular}


Table 2

The Nine Words Selected to be Titles Differing in Emotional Content

\begin{tabular}{lll}
\hline Positive & Negative & Neutral \\
\hline Kiss & Suicide & Taxi \\
Passion & Tragedy & Window \\
Champion & Murderer & Sphere \\
\hline
\end{tabular}




\section{Figure 1}

\section{The Effect of Linguistic Fluency on the Six Rating Scale}

How likely would you be to go to a concert of the artist?

How likely would you be to recommend the song to a friend?

How likely is that the song is going to be commercially successful?

How would you rate the musical quality of the song?

How well does the artist convey emotions through music?

How much did you like the song?
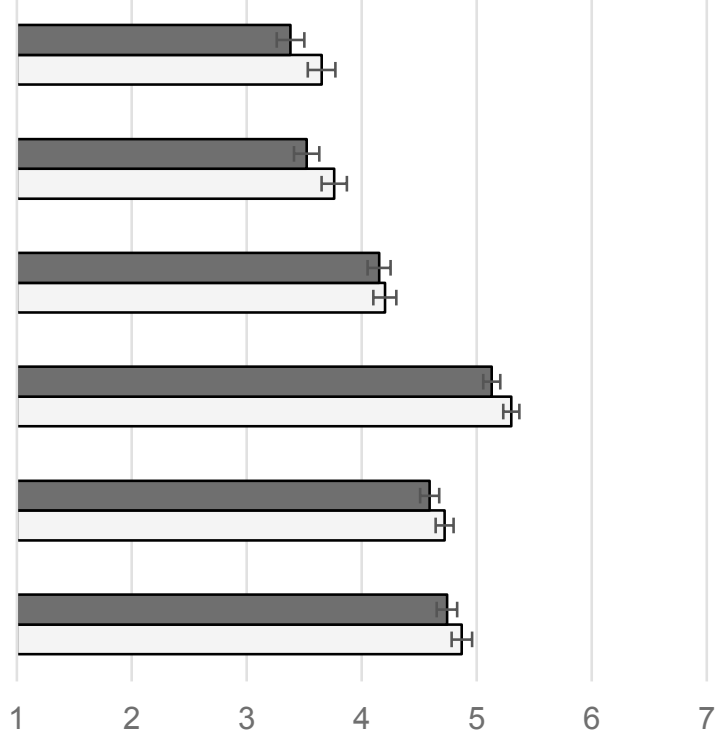

口Disfluent aFluent

Note. Error bars represent the standard error 
Figure 2

Participants' Rating Scores in the Three Dimensions of Music Evaluation

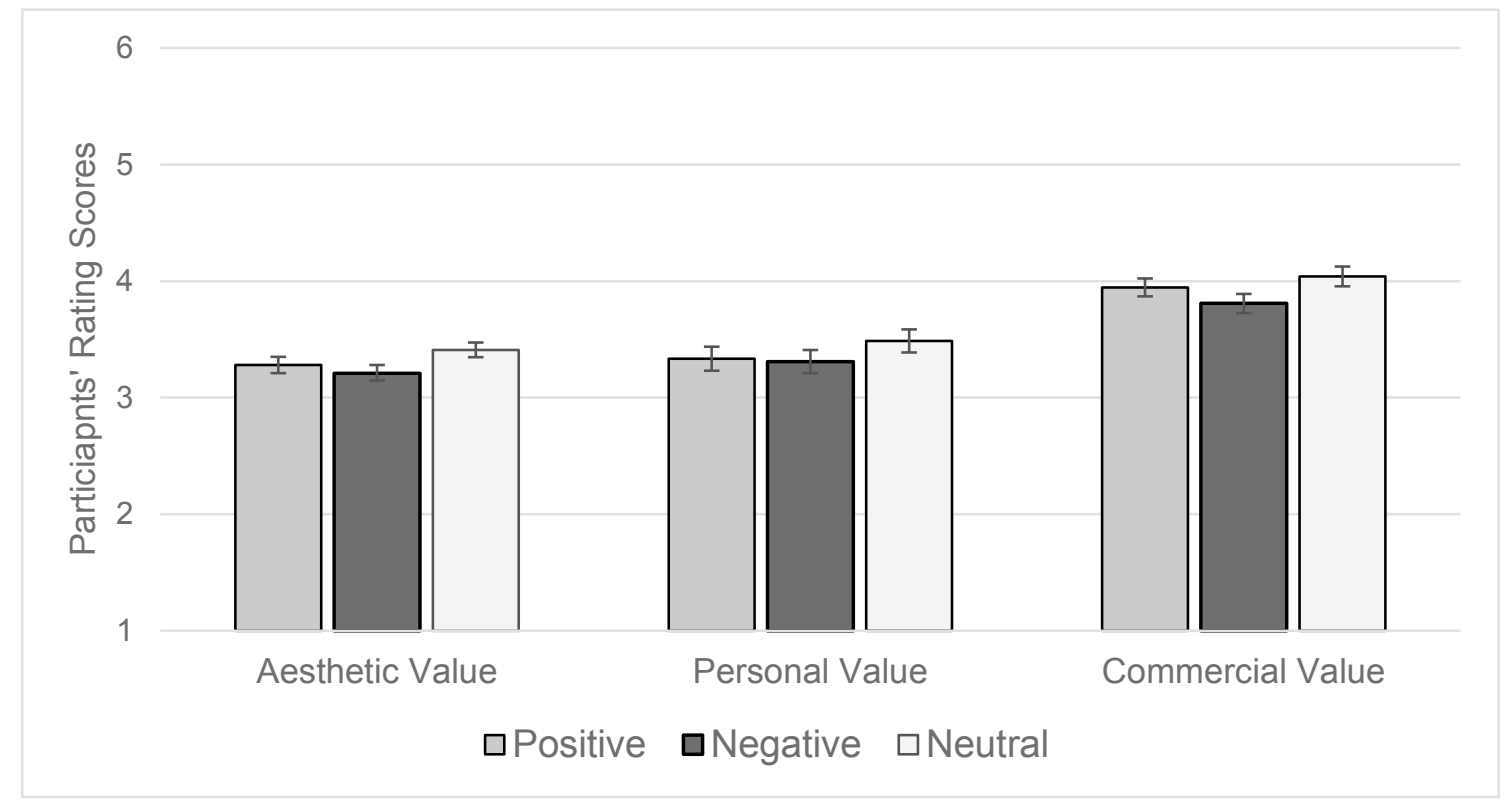

Note. Error bars represent the standard error 
Figure 3

Participants' Number of Remembered Titles

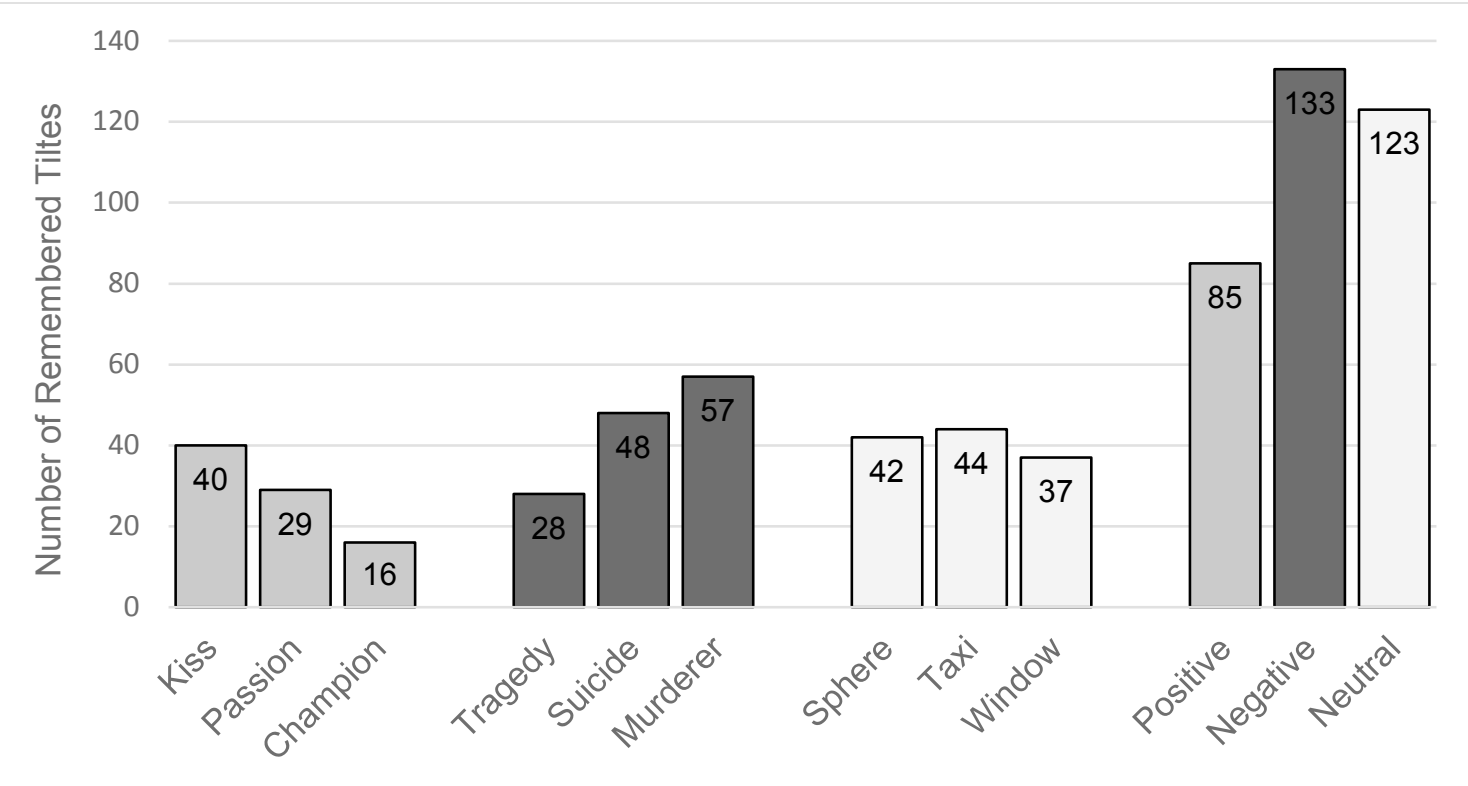


Figure 4

Participants' Ratings in the Four Title Conditions

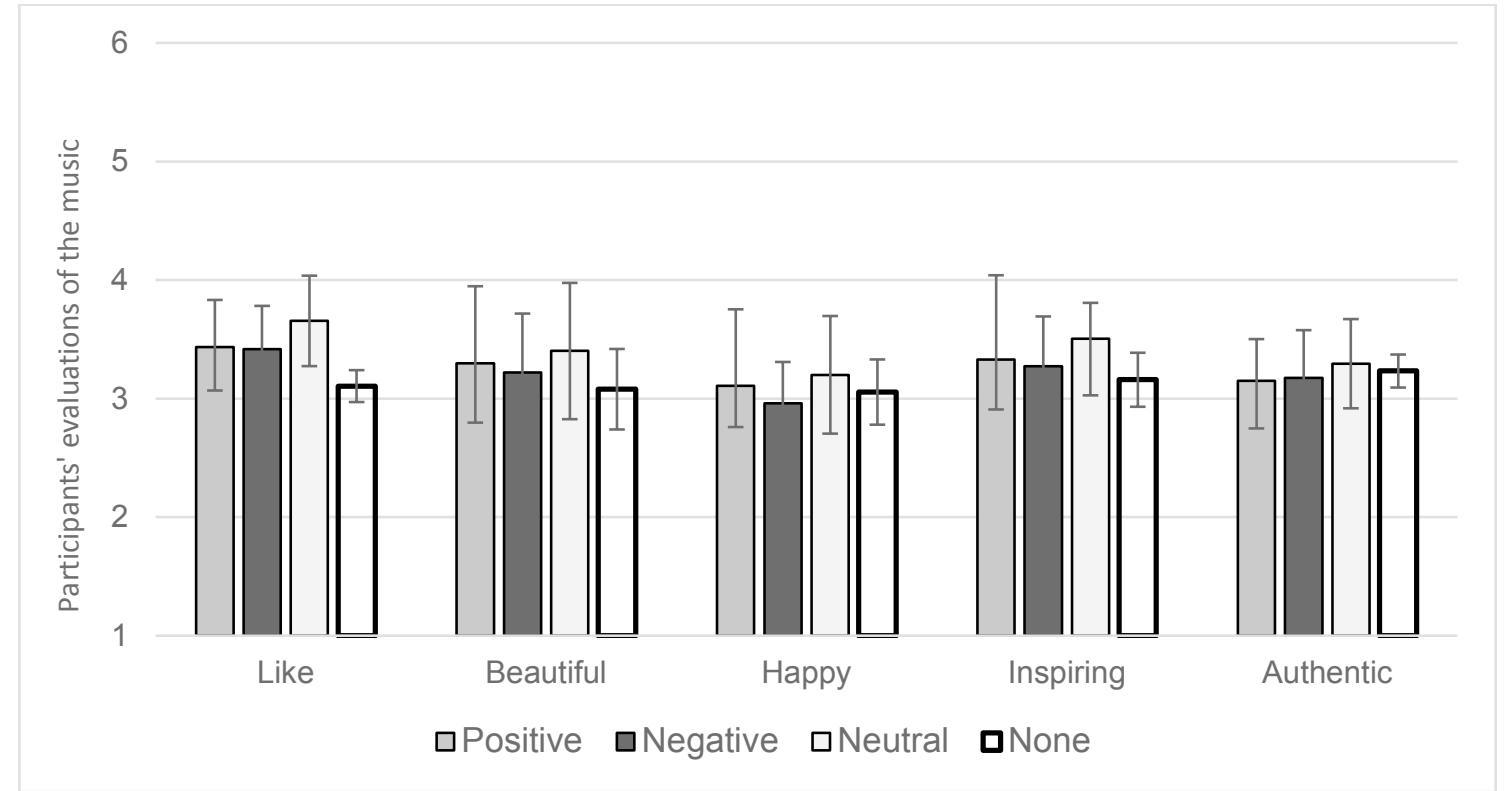

* Error bars represent the Confidence Intervals extracted from the mixed-effect models 
Appendix A

Summary of Principal Component Analysis for the Six Rating Scales

\begin{tabular}{|c|c|}
\hline Rating Scales & Component 1 \\
\hline How much did you like the song? & .87 \\
\hline $\begin{array}{l}\text { How well does the artist convey } \\
\text { emotions through music? }\end{array}$ & .78 \\
\hline $\begin{array}{l}\text { How would you rate the musical } \\
\text { quality of the song? }\end{array}$ & .78 \\
\hline $\begin{array}{l}\text { How likely is that the song is going to } \\
\text { be commercially successful? }\end{array}$ & .61 \\
\hline How likely would you be to & .87 \\
\hline recommend the song to a friend? & \\
\hline $\begin{array}{l}\text { How likely would you be to go to a } \\
\text { concert of the artist? }\end{array}$ & .86 \\
\hline Eigenvalues & 3.85 \\
\hline$\%$ of variance & 64.26 \\
\hline
\end{tabular}


Appendix B

Summary Table of the LME Model with Linguistic Fluency

\begin{tabular}{lllll}
\hline & Sum of Sq & df & F & $p$ \\
\hline Main Model & 2.86 & 1 & 4.37 & $.04^{*}$ \\
\hline
\end{tabular}


Appendix C

Scores of the Nine Selected Music Excerpts on the Different Evaluative Dimensions

\begin{tabular}{lllllll}
\hline Music & Familiarity & Liking & Beautiful & Inspiring & Authentic & Happy \\
excerpt & & & & & & \\
\hline 1 & $1.32(0.67)$ & $3.24(1.48)$ & $3.31(1.37)$ & $3.30(1.43)$ & $3.24(1.28)$ & $3.20(1.01)$ \\
2 & $1.46(0.92)$ & $3.04(1.61)$ & $3.41(1.30)$ & $2.94(1.44)$ & $3.19(1.30)$ & $3.07(1.35)$ \\
3 & $1.51(0.99)$ & $2.94(1.54)$ & $3.00(1.49)$ & $3.23(1.57)$ & $3.30(1.54)$ & $2.67(1.37)$ \\
4 & $1.74(1.14)$ & $3.19(1.58)$ & $2.61(1.45)$ & $2.81(1.34)$ & $3.15(1.22)$ & $3.05(1.35)$ \\
5 & $1.63(1.19)$ & $3.41(1.56)$ & $3.71(1.36)$ & $3.59(1.50)$ & $3.60(1.36)$ & $3.26(1.27)$ \\
6 & $1.61(1.07)$ & $2.91(1.59)$ & $2.56(1.37)$ & $2.97(1.53)$ & $2.84(1.31)$ & $3.11(1.27)$ \\
7 & $1.63(1.13)$ & $2.89(1.52)$ & $2.31(1.36)$ & $2.79(1.38)$ & $3.20(1.55)$ & $2.78(1.37)$ \\
8 & $1.67(1.12)$ & $3.04(1.41)$ & $3.12(1.58)$ & $3.16(1.48)$ & $2.95(1.46)$ & $3.08(1.60)$ \\
9 & $1.68(1.07)$ & $3.28(1.61)$ & $3.66(1.53)$ & $3.62(1.53)$ & $3.56(1.39)$ & $3.38(1.33)$
\end{tabular}

*Standard Deviation in brackets 
Appendix D

Affective, Semantic, and Lexical Characteristics of the Nine Words Selected to be

Titles

\begin{tabular}{llll}
\hline Linguistic variables & Positive & Negative & Neutral \\
\hline Valence & $8.24(0.21)$ & $1.52(0.26)$ & $5.41(0.46)$ \\
Valence Magnitude & $3.24(0.20)$ & $3.48(0.26)$ & $0.46(0.26)$ \\
Arousal & $6.81(0.83)$ & $6.48(0.89)$ & $3.75(0.31)$ \\
Relative Frequency & $27.30(6.06)$ & $14.38(5.67)$ & $43.94(49.72)$ \\
Log. Frequency & $1.44(0.09)$ & $1.16(0.19)$ & $1.36(0.29)$ \\
Length & $6.33(2.08)$ & $7.33(0.57)$ & $5.33(1.15)$ \\
Concreteness & $3.26(1.11)$ & $3.16(0.95)$ & $4.74(0.26)$ \\
Plausibility & $3.55(0.18)$ & $2.97(0.22)$ & $3.19(0.36)$ \\
\hline
\end{tabular}

*Standard Deviation in brackets 


\section{Appendix E}

Summary of Principal Component Analyses for Aesthetic Value, Personal Value, and Estimated Commercial Value

Principal Component Analysis for the Five Ratings Measuring Aesthetic Value

Rating Scales Component 1

How much did you like the music excerpt? - .89

Like

To what degree each of the following attributes $\quad .86$

fits the song - Beautiful

To what degree each of the following attributes $\quad .86$

fits the song - Inspiring

To what degree each of the following attributes $\quad .60$

fits the song - Happy

To what degree each of the following attributes $\quad .83$

fits the song - Authentic

Eigenvalues $\quad 3.33$

$\%$ of variance $\quad 66.66$ 
Principal Component Analysis for the Three Ratings Measuring Personal Value

\begin{tabular}{ll}
\hline Rating Scales & Component 1 \\
\hline I want to find out more about the artists of the & .93 \\
song & .92 \\
I would share the song with my friends & .92 \\
I want to see the artist of the song play live & 2.56 \\
Eigenvalues & 85.34 \\
\% of variance
\end{tabular}

Principal Component Analysis for the Three Ratings Measuring Estimated Commercial Value

\begin{tabular}{lll}
\hline Rating Scales & Component 1 \\
\hline The song has the potential to succeed & .91 \\
commercially & \\
I think the song comes from a successful artist & .89 \\
I think many people would like the song & .86 \\
Eigenvalues & 2.37 \\
\% of variance & 78.97 \\
\hline
\end{tabular}


Appendix F

Summary Table of the Mixed-Effect Models in Experiment 2

\begin{tabular}{lllll}
\hline & Sum of Sq & df & F & p \\
\hline Model with Aesthetic Value & 6.97 & 2 & 3.68 & $.02^{*}$ \\
Model with Personal Value & 5.08 & 2 & 1.34 & .26 \\
Model with Commercial Value & 7.77 & 2 & 3.77 & $.02^{*}$ \\
Model with Number of & 7.14 & 2 & 7.19 & $<.001^{* * *}$ \\
Remembered Titles (Memory) & & & & \\
\end{tabular}


Appendix G

Summary Table of the Mixed-Effect Models with the STOMP Preference Factor for Energetic and Rhythmic Music

\begin{tabular}{lllll}
\hline & Sum of Sq & df & F & $\mathrm{p}$ \\
\hline Aesthetic Value & & & & \\
Emotionality of Titles & 6.09 & 2 & 3.70 & $.02^{*}$ \\
Energetic and Rhythmic Music & 3.35 & 1 & 4.08 & $.04^{*}$ \\
Remembered Titles & & & & \\
Emotionality of Titles & 13.09 & 2 & 10.94 & $<.001$ \\
Energetic and Rhythmic Music & 3.60 & 1 & 5.59 & $.02^{*}$ \\
\hline
\end{tabular}


Appendix H

Summary Table of the Mixed-Effect Models with the Four Title Conditions (Negative,

Positive, Neutral, and Non-title)

\begin{tabular}{lllll}
\hline & Sum of Sq & df & $\mathrm{F}$ & $\mathrm{p}$ \\
\hline Like & 29.69 & 3 & 6.42 & $<.001^{* * *}$ \\
Beautiful & 10.58 & 3 & 2.67 & $.04^{*}$ \\
Happy & 7.98 & 3 & 2.35 & .07 \\
Inspiring & 12.90 & 3 & 3.01 & $.03^{*}$ \\
Authentic & 3.23 & 3 & .86 & .46 \\
\hline
\end{tabular}

